\title{
Shared spatial representations for physical locations and location words in bilinguals' primary language
}

\author{
Kim-Phuong L. Vu, Thuan K. Ngo, and Katsumi Minakata \\ California State University, Long Beach, California \\ AND \\ Robert W. Proctor \\ Purdue University, West Lafayette, Indiana
}

\begin{abstract}
For monolinguals, the Simon effect is eliminated when Simon task trials are intermixed with ones in which participants respond to the words left and right with incompatibly mapped keypresses. For bilingual Dutch/ French speakers, this result has been shown to occur when the words are in Dutch (their first and primary language), but not when they are in French. To dissociate the influence of order in which the languages were learned from whether the language was the primary one currently being used, we tested bilinguals who learned Spanish or Vietnamese as their first language but for whom English became their primary language. For both groups, the incompatible location-word mapping influenced performance of the Simon task when the words were in English but not when they were in the first language. These findings indicate that the strength of language, not order of acquisition, is the critical factor.
\end{abstract}

The cognitive processing of persons fluent in two languages has received considerable research interest, resulting in an entire handbook devoted to the topic (Kroll \& De Groot, 2005). Lexical decision and naming tasks, often coupled with priming procedures, have been used to assess how meaning is represented in the first and second languages. A common finding is that of processing asymmetry, in which the first language tends to dominate the second (e.g., Kroll \& Stewart, 1994). For example, when a semantically related prime word is in one language and the target word to be classified or named is in another language, stronger priming effects occur from the first to the second language than in the opposite direction (Schoonbaert, Duyck, Brysbaert, \& Hartsuiker, 2009). A popular model developed to explain such results is that of Kroll and Stewart, which specifies distinct lexical systems for the first and second languages. In the model, both lexical systems have links to a common conceptual system, but those links are weaker for the second language than for the first.

Evidence of processing asymmetry for spatial information in the first and second languages was reported by Notebaert, De Moor, Gevers, and Hartsuiker (2007), using a method in which trials of a Simon task (Simon, 1990) for which stimulus location was irrelevant were mixed with trials of a task for which the meaning of a location word was relevant. For the Simon task, left and right keypress responses were assigned to the colors of red and green cir- cles, presented randomly in left and right locations. When performed alone, this task yields a correspondence effect for stimulus and response locations called the Simon effect, for which reaction time (RT) is shorter when the locations correspond than when they do not (Lu \& Proctor, 1995). For the task in which location information was relevant, the location words left and right were presented at the center of the display screen and were mapped incompatibly to the right and left keypresses. For monolingual participants, random intermixing of trials from the incompatibly mapped location-relevant tasks with trials from the Simon task results in an elimination of the Simon effect or a reversal to favor the noncorresponding response (Proctor, Marble, \& Vu, 2000; Proctor \& Vu, 2002). This influence of the incompatible location-word mapping on Simon task performance suggests that verbospatial information and visuospatial information share a semantic/conceptual representation, with stimuli in the Simon task tending to activate the response linked to the shared representation for the task of responding to location words.

Notebaert et al. (2007) showed that, for bilingual participants, this influence of an incompatible location-word mapping on the Simon effect occurred only when the words were from the first language. For bilingual Dutch/ French participants, the Simon effect for the locationirrelevant stimuli reversed in the first of four trial blocks when the words were in the participants' first language 
(Dutch), with this effect decreasing to no difference between corresponding and noncorresponding trials across blocks. However, when the words were in the second language (French), a positive Simon effect was evident for all trial blocks. Notebaert et al. interpreted these results in a manner consistent with Kroll and Stewart's (1994) language activation model: The shared semantic/conceptual representation receives only weak activation from the lexical system for second-language location words.

Two characteristics of Notebaert et al.'s (2007) bilingual participants are noteworthy. First, the participants did not start to learn their nonnative language, French, until an average age of 10 years, whereas some bilinguals learn both languages earlier in life. Because proficiency in a second language correlates negatively with the time at which the language is first learned (Birdsong, 2005), the possibility exists that strong lexical-semantic links between the words in the second language and the intermediate spatial representations develop for bilingual participants who have spoken both languages since early childhood. Second, Dutch was the participants' primary language used in everyday life, as well as the first language learned. Consequently, Notebaert et al.'s study does not allow determination of whether the critical factor is that a language be the first learned, or that it be the primary language currently used by the participants.

To determine whether the critical factor is the language first learned or the primary language used, we conducted two experiments for which the bilingual participants came from two ethnic groups in the U.S. who learned to speak their native language first but for whom English became their primary language: Spanish/English and Vietnamese/ English participants. This allowed us to determine whether the bilingual participants showed evidence of shared verbal and physical spatial representations in both languages or only one, and if the latter, whether that language would be the first learned (Spanish or Vietnamese) or the primary language (English). If the Simon effect were eliminated for the native language but not for the primary one, the implication would be that links between representations established early in life become "hardwired" and have precedence on the processing of spatial information later in life. In contrast, if the Simon effect were eliminated for the primary language but not for the native language, the implication would be that frequency of experience with the language is the main determinant of the strengths of the links between representations (see, e.g., BasnightBrown \& Altarriba, 2007; Fillmore, 2005).

We also included monolingual control groups in each experiment to allow us to obtain evidence regarding whether monolinguals and bilinguals process information differently. For example, it has been suggested that bilinguals have developed more efficient executive control processes than monolinguals because they need to coordinate the two languages (e.g., Bialystok, Craik, Klein, \& Viswanathan, 2004). With regard to the Simon task, Bialystok et al., having found that bilingual persons showed faster responding overall and smaller Simon effects than monolinguals did, concluded, "The executive processes required to manage their [bilinguals'] two language systems are invoked as well in the Simon task" (p. 302). The method used in the present study, where location-irrelevant trials of the Simon task are mixed with trials requiring incompatible responses to location words, should demand more in the way of executive control processes than should the Simon task alone. Consequently, if bilinguals possess more efficient executive control processes, their performance in a mixed tasks environment should benefit from this greater efficiency.

In addition, within the Simon task, Bialystok (2006) assumed that conditions for which a large proportion of trials involve response switches "increase processing demands on the monitoring and switching aspects of executive functioning, making the task more difficult to perform" (p. 71). The mixed tasks environment used in the present study is more difficult than single task environments (Proctor \& Vu, 2006), and mixing tasks, by its nature, requires increased processing demands on monitoring and switching (see Stürmer, Leuthold, Soetens, Schröter, \& Sommer, 2002). Therefore, we also examined sequential effects to determine whether costs associated with switching tasks from one trial to the next are less for bilinguals than for monolinguals.

\section{EXPERIMENT 1}

The design of Experiment 1 followed that described in Notebaert et al. (2007) closely, with the main difference being the languages of the bilingual participants and stimuli and the inclusion of a monolingual control group. The bilingual participants were fluent in both Spanish and English, whereas the monolingual participants were fluent only in English. We expected that, compared with monolingual English control participants who should have little experience with the Spanish words, the bilingual participants would show longer RTs to incompatibly mapped words in their native language, because the spatial meaning of the location word was opposite that of the assigned response. All bilingual participants indicated that Spanish was the first language they had learned, but that English was now their primary language. This distinction allowed us to determine whether the critical factor in the different effect patterns found by Notebaert et al. was that the Dutch language was learned first by their participants or that it was their primary language.

\section{Method}

Participants. Fifty-six participants were recruited from California State University Long Beach and its surrounding community through the Psychology Department participant pool, fliers, and word-ofmouth recruitments. Twenty-eight participants ( 9 males, 19 females) were bilingual Spanish/English speakers (26 categorized as Hispanic, and 2 as Hispanic/Asian). All bilingual participants reported learning to speak Spanish as their first language, with English learned soon after; English is now their primary language. The remaining 28 participants ( 3 males, 25 females) were monolingual English speakers (3 Asian, 14 Caucasian, 5 African American, 6 mixed race), all of whom indicated that English was their only language. Introductory psychology students received experimental credits toward their research requirement, and other participants were paid $\$ 15$.

Apparatus and Stimuli. Micro Experimental Laboratory (MEL v. 2.01) was used to program all components of the experiment, including stimulus presentation, timing of events, record- 
ing responses, and presenting the instructions. The program was run on a personal computer with a 14-in. VGA color monitor. The participants were tested individually in a dimly lit room directly in front of the monitor, at a viewing distance of $55 \mathrm{~cm}$. For both tasks, participants responded by pressing the " $\mathrm{Z}$ " or "/" key of a standard QWERTY keyboard, aligned to the center of the monitor, with the left and right index finger, respectively. For the English location words, the stimuli were the words left and right presented in uppercase letters at the center of the screen (approximate size of $12 \times$ $5 \mathrm{~mm}$ and $15 \times 5 \mathrm{~mm}$, or $1.25^{\circ} \times 0.52^{\circ}$ and $1.56^{\circ} \times 0.52^{\circ}$, respectively). For the Spanish location words, the stimuli were the words izquierda and derecha presented in uppercase letters at the center of the screen (approximate size of $27 \times 5 \mathrm{~mm}$ and $21 \times 5 \mathrm{~mm}$, or $2.81^{\circ} \times 0.52^{\circ}$ and $2.19^{\circ} \times 0.52^{\circ}$, respectively). For both languages, the location-irrelevant (Simon) stimuli were filled red and green (MEL color codes of 4 and 2, respectively) circles of $5 \mathrm{~cm}\left(0.52^{\circ}\right)$ in diameter, centered on a location approximately $7.6 \mathrm{~cm}$ to the left or right of the screen center.

Procedure. Participants performed the two intermixed tasks within a session lasting approximately $1.5 \mathrm{~h}$. For the locationrelevant task, participants were instructed to make the keypress response opposite to the meaning of the location word. For the location-irrelevant task, participants were instructed to make the keypress response assigned to the color of the circles, while ignoring the stimulus location. For half the participants, green was assigned to the left response and red to the right response; for the other half, the assignment was reversed. Each participant performed two parts, one with each language, with language order counterbalanced between subjects. Monolinguals were told that izquierda was the Span- ish word for left and that derecha was the Spanish word for right, and that they were to press the key assigned to each word.

Participants were instructed to respond as quickly and accurately as possible. RT was measured from stimulus onset to the depression of a response key. The stimulus remained present until a response was made, and the intertrial interval (ITI) was $1 \mathrm{sec}$. A 400-Hz error tone was presented for $500 \mathrm{msec}$ for incorrect responses, followed by the 1-sec ITI. Within each of the two parts, there were four blocks of 176 trials ( 88 location-relevant trials and 88 Simon trials, randomly intermixed; see Figure 1), for which the first 20 trials of the first block were eliminated as practice. Within each block, the two location words were presented equally often in random order. Similarly, the four color and location combinations for the location-irrelevant task occurred equally often, in a randomized order. Also, in computing RT and percent error (PE), trials with RT less than $200 \mathrm{msec}$ or greater than $2,000 \mathrm{msec}$ were excluded as outliers $(<2 \%$ of all trials).

After completing the RT tasks, participants were asked to fill out a demographic questionnaire and take a short vocabulary test (see Table 1 for a summary of means; see the Appendix for statistical comparisons of the two groups). For bilingual participants, the vocabulary test was a four-choice recognition test in which 20 common words (e.g., dog, tree, left, right, etc.) were printed, 10 in English, 10 in Spanish. Participants were asked to circle each English word's equivalent in Spanish, and vice versa for the remaining 10. For monolingual participants, the vocabulary test also contained 20 common words, with 10 in Spanish and 10 in Vietnamese-the second language used in Experiment 2-to allow comparison with the monolingual control group of that experiment. For the monolinguals,

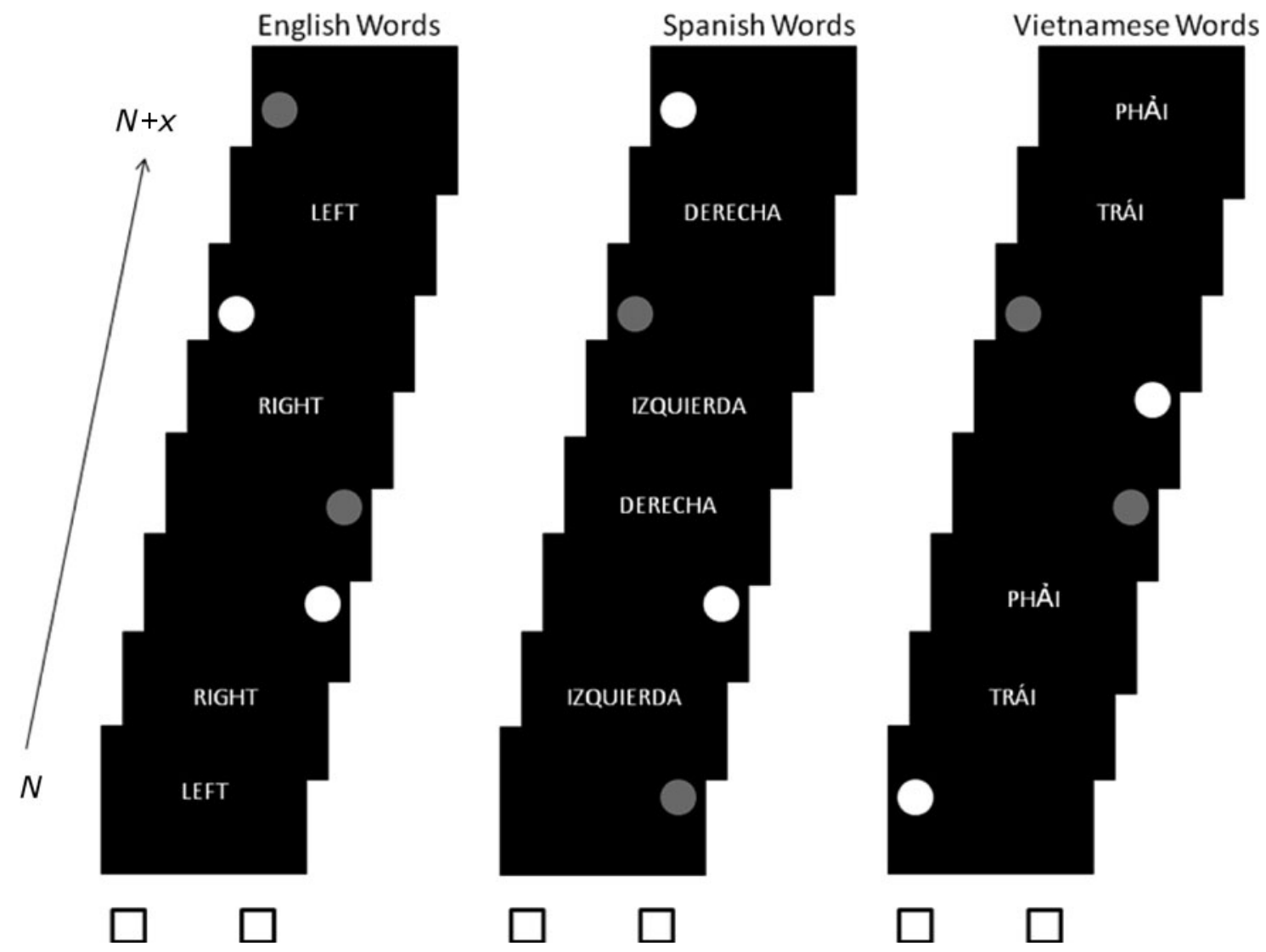

Figure 1. Illustration of the procedure used in Experiments 1 and 2. English words were mixed with Simon trials for one part of both experiments. In the other part, Spanish words were mixed with Simon trials in Experiment 1 and Vietnamese words with Simon trials in Experiment 2. For the Simon trials, red and green circles are depicted in the figure by white and gray. The two trial types were randomly intermixed. 
Table 1

Demographic Information (Means and Standard Deviations) for Monolingual and Bilingual Participants in Experiments 1 and 2

\begin{tabular}{|c|c|c|c|c|c|c|c|c|}
\hline \multirow[b]{4}{*}{ Item } & \multicolumn{8}{|c|}{ Experiment } \\
\hline & \multicolumn{4}{|c|}{ 1: English/Spanish } & \multicolumn{4}{|c|}{ 2: English/Vietnamese } \\
\hline & \multicolumn{2}{|c|}{ Monolinguals } & \multicolumn{2}{|c|}{ Bilinguals } & \multicolumn{2}{|c|}{ Monolinguals } & \multicolumn{2}{|c|}{ Bilinguals } \\
\hline & $M$ & $S D$ & $M$ & $S D$ & $M$ & $S D$ & $M$ & $S D$ \\
\hline Mean age & 19.6 & 2.9 & 19.8 & 2.1 & 20.1 & 3.2 & 21.9 & 3.4 \\
\hline Years spoken English & 18.7 & 2.9 & 16.0 & 3.0 & 19.1 & 3.0 & 17.3 & 4.5 \\
\hline Spoken English fluency & 9.6 & 1.5 & 9.3 & 1.1 & 9.8 & 0.6 & 9.0 & 1.1 \\
\hline Years reading English & 15.2 & 4.0 & 14.9 & 2.7 & 16.1 & 3.3 & 16.0 & 4.1 \\
\hline Reading English fluency & 9.9 & 0.5 & 9.3 & 1.3 & 9.7 & 0.7 & 8.8 & 1.1 \\
\hline Years spoken Spanish & $\mathrm{n} / \mathrm{a}$ & $\mathrm{n} / \mathrm{a}$ & 18.0 & 2.9 & $\mathrm{n} / \mathrm{a}$ & $\mathrm{n} / \mathrm{a}$ & $\mathrm{n} / \mathrm{a}$ & $\mathrm{n} / \mathrm{a}$ \\
\hline Spoken Spanish fluency & $\mathrm{n} / \mathrm{a}$ & $\mathrm{n} / \mathrm{a}$ & 8.4 & 1.6 & $\mathrm{n} / \mathrm{a}$ & $\mathrm{n} / \mathrm{a}$ & $\mathrm{n} / \mathrm{a}$ & $\mathrm{n} / \mathrm{a}$ \\
\hline Years reading Spanish & $\mathrm{n} / \mathrm{a}$ & $\mathrm{n} / \mathrm{a}$ & 14.4 & 4.4 & $\mathrm{n} / \mathrm{a}$ & $\mathrm{n} / \mathrm{a}$ & $\mathrm{n} / \mathrm{a}$ & $\mathrm{n} / \mathrm{a}$ \\
\hline Reading Spanish fluency & $\mathrm{n} / \mathrm{a}$ & $\mathrm{n} / \mathrm{a}$ & 8.1 & 1.8 & $\mathrm{n} / \mathrm{a}$ & $\mathrm{n} / \mathrm{a}$ & $\mathrm{n} / \mathrm{a}$ & $\mathrm{n} / \mathrm{a}$ \\
\hline Years spoken Vietnamese & $\mathrm{n} / \mathrm{a}$ & $\mathrm{n} / \mathrm{a}$ & $\mathrm{n} / \mathrm{a}$ & $\mathrm{n} / \mathrm{a}$ & $\mathrm{n} / \mathrm{a}$ & $\mathrm{n} / \mathrm{a}$ & 20.3 & 4.6 \\
\hline Spoken Vietnamese fluency & $\mathrm{n} / \mathrm{a}$ & $\mathrm{n} / \mathrm{a}$ & $\mathrm{n} / \mathrm{a}$ & $\mathrm{n} / \mathrm{a}$ & $\mathrm{n} / \mathrm{a}$ & $\mathrm{n} / \mathrm{a}$ & 7.0 & 2.2 \\
\hline Years reading Vietnamese & $\mathrm{n} / \mathrm{a}$ & $\mathrm{n} / \mathrm{a}$ & $\mathrm{n} / \mathrm{a}$ & $\mathrm{n} / \mathrm{a}$ & $\mathrm{n} / \mathrm{a}$ & $\mathrm{n} / \mathrm{a}$ & 11.4 & 7.5 \\
\hline Reading Vietnamese fluency & $\mathrm{n} / \mathrm{a}$ & $\mathrm{n} / \mathrm{a}$ & $\mathrm{n} / \mathrm{a}$ & $\mathrm{n} / \mathrm{a}$ & $\mathrm{n} / \mathrm{a}$ & $\mathrm{n} / \mathrm{a}$ & 4.8 & 3.0 \\
\hline Spanish vocabulary score & 6.2 & 1.6 & 9.9 & 0.3 & 7.0 & 1.4 & $\mathrm{n} / \mathrm{a}$ & $\mathrm{n} / \mathrm{a}$ \\
\hline Vietnamese vocabulary score & 3.3 & 2.2 & $\mathrm{n} / \mathrm{a}$ & $\mathrm{n} / \mathrm{a}$ & 3.2 & 2.0 & 9.9 & 0.3 \\
\hline
\end{tabular}

Note-Fluency scores are based on a 10 -point Likert scale $(1=$ not fluent; $10=$ very fluent $)$. The vocabulary scores are numbers correct out of 10 ; for the bilingual groups, this number is the mean of the two sets for the different directions of translation.

the demographic questionnaire consisted of questions relating to how many years they have been able to speak and read in English, as well as a fluency rating $(1=$ not fluent to $10=$ very fluent $)$. Monolingual participants also indicated that they did not speak or read Spanish. Bilingual Spanish participants were asked the same questions about their usage and fluency of Spanish as well as of English.

\section{Results}

Location-relevant trials. Mean RT and PE were submitted to 2 (language: words in English or Spanish) $\times$ 2 (group: Spanish/English bilinguals or English monolinguals) $\times 4$ (block: $1-4$ ) ANOVAs, with group as the only between-subjects variable. For this and subsequent analyses, we report the original degrees of freedom but used the Huynh-Feldt correction to the $p$ value for violations of sphericity where appropriate.

For both RT and PE, the main effect of block was significant $\left[F \mathrm{~s}(3,162)=32.09\right.$ and $6.79, M S_{\mathrm{e}} \mathrm{s}=4,368$ and $5.98, p \mathrm{~s}<.001]$. Participants showed a practice effect in which RT and PE decreased from the first block $(M \mathrm{~s}=$ $789 \mathrm{msec}$ and $5.28 \%)$ to the last one $(M \mathrm{~s}=708 \mathrm{msec}$ and $3.93 \%$ ). Block did not enter into any interactions with other factors.

The main effect of group was significant for RT $\left[F(1,54)=21.98, M S_{\mathrm{e}}=68,185, p<.001\right]$, as was the main effect of language for both measures $[F \mathrm{~s}(1,54)=$ 24.82 and 40.74, $M S_{\mathrm{e}} \mathrm{s}=28,101$ and 11.08, $\left.p \mathrm{~s}<.001\right]$. RT was shorter for the monolinguals $(M=680 \mathrm{msec})$ than for the bilinguals $(M=796 \mathrm{msec})$. Moreover, RT was shorter and errors fewer with Spanish words $(M \mathrm{~s}=$ $699 \mathrm{msec}$ and 3.13\%) than with English words ( $M \mathrm{~s}=$ $777 \mathrm{msec}$ and 5.84\%). Group interacted with language for both measures $\left[F \mathrm{~s}(1,54)=7.14\right.$ and $11.08, M S_{\mathrm{e}} \mathrm{s}=$ 28,101 and 20.30, $p$ s $<.010]$. Monolinguals showed shorter RT than bilinguals did for the English words $(M \mathrm{~s}=741 \mathrm{msec}, 814 \mathrm{msec})$, but this difference was larger for the Spanish words $(M \mathrm{~s}=620 \mathrm{msec}, 778 \mathrm{msec})$. The monolinguals showed a higher error rate than the bilinguals did for English words ( $M \mathrm{~s}=6.78 \%$ and $4.91 \%$ ), but for Spanish words this shifted to a lower error rate for the monolinguals $(M \mathrm{~s}=2.65 \%$ and $3.61 \%)$. No other effects were significant.

Location-irrelevant trials (Simon task). Mean correct RT and PE for the location-irrelevant trials were submitted to analyses similar to those for the location-relevant trials, but with correspondence (corresponding or noncorresponding) as an additional within-subjects variable.

The main effect of block was significant for RT only $\left[F(3,162)=35.60, M S_{\mathrm{e}}=5,781, p<.001\right]$, as were those of correspondence and group $[F \mathrm{~s}(1,54)=6.65$ and 10.34, $M S_{\mathrm{e}} \mathrm{s}=2,309$ and 163,287, $\left.p \mathrm{~s}<.015\right]$. RT decreased from the first block $(M=774 \mathrm{msec})$ to the last one

Table 2

Mean Reaction Time (RT) and Percent Error (PE) for Location-Relevant Trials As a Function of Group, Language, and Block in Experiment 1

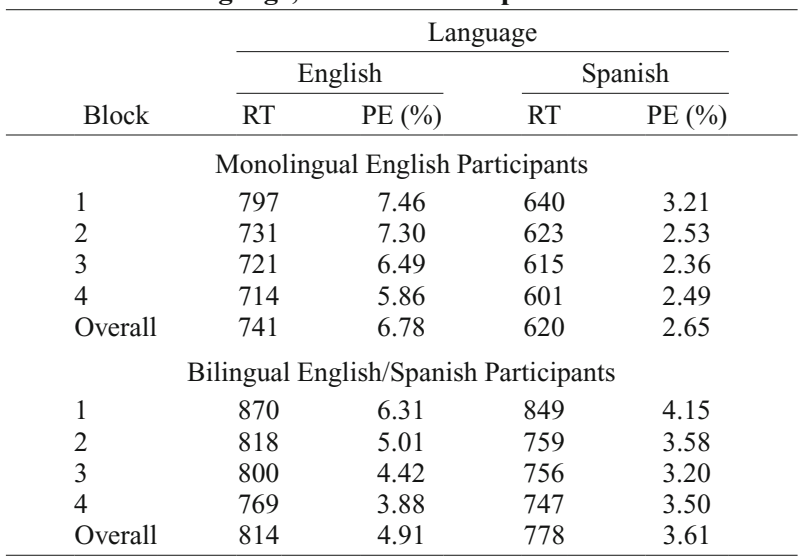


Table 3

Mean Reaction Time (RT) and Percent Error (PE)

As a Function of Group, Language, Correspondence, and Block for Location-Irrelevant Trials in Experiment 1

\begin{tabular}{|c|c|c|c|c|c|c|c|c|}
\hline \multirow[b]{3}{*}{ Block } & \multicolumn{4}{|c|}{ Intermixed English Words } & \multicolumn{4}{|c|}{ Intermixed Spanish Words } \\
\hline & \multicolumn{2}{|c|}{ Corresp. } & \multicolumn{2}{|c|}{ Noncorresp. } & \multicolumn{2}{|c|}{ Corresp. } & \multicolumn{2}{|c|}{ Noncorresp. } \\
\hline & RT & PE $(\%)$ & RT & PE $(\%)$ & RT & PE $(\%)$ & RT & PE $(\%)$ \\
\hline \multicolumn{9}{|c|}{ Monolingual English Participants } \\
\hline 1 & 771 & 4.79 & 758 & 3.47 & 673 & 4.28 & 687 & 6.63 \\
\hline 2 & 695 & 3.59 & 703 & 4.36 & 657 & 4.90 & 672 & 5.24 \\
\hline 3 & 700 & 4.03 & 701 & 3.85 & 663 & 4.58 & 658 & 5.99 \\
\hline 4 & 671 & 2.53 & 692 & 4.42 & 639 & 5.06 & 659 & 5.34 \\
\hline Overall & 709 & 3.73 & 714 & 4.02 & 658 & 4.70 & 669 & 5.80 \\
\hline \multicolumn{9}{|c|}{ Bilingual English/Spanish Participants } \\
\hline 1 & 868 & 4.11 & 848 & 3.80 & 790 & 3.25 & 798 & 4.50 \\
\hline 2 & 802 & 2.67 & 794 & 3.15 & 730 & 3.56 & 749 & 4.61 \\
\hline 3 & 786 & 2.99 & 791 & 2.53 & 721 & 3.18 & 747 & 4.80 \\
\hline 4 & 734 & 2.40 & 751 & 2.67 & 726 & 2.89 & 751 & 4.84 \\
\hline Overall & 798 & 3.04 & 796 & 3.04 & 742 & 3.22 & 761 & 4.69 \\
\hline
\end{tabular}

( $M=703 \mathrm{msec})$; it was shorter for corresponding $(M=$ $727 \mathrm{msec})$ than for noncorresponding $(M=735 \mathrm{msec})$ trials and for monolinguals $(M=687 \mathrm{msec})$ than for bilinguals $(M=774 \mathrm{msec})$. The main effect of language was significant for both $\mathrm{RT}$ and $\mathrm{PE}\left[F_{\mathrm{S}}(1,54)=25.09\right.$ and $15.66, M S_{\mathrm{e}} \mathrm{s}=19,403$ and $\left.18.69, p \mathrm{~s}<.001\right]$. RT was shorter when the intermixed location-relevant trials used Spanish words $(M=707 \mathrm{msec})$ than when they used English words $(M=754 \mathrm{msec})$, but PE was higher (with Spanish words, $M=4.60 \%$; with English words, $M=$ $3.46 \%$ ), indicating a greater bias toward speed at the cost of accuracy when the intermixed words were Spanish.

Block also entered into two-way interactions with correspondence $\left[F(3,162)=3.63, M S_{\mathrm{e}}=1,451, p<\right.$ $.015]$ and language $\left[F(3,162)=4.53, M S_{\mathrm{e}}=8,346, p<\right.$ $.010]$ for RT. For the first interaction, the Simon effect was larger in the last trial block $(M=21 \mathrm{msec})$ than in the first three blocks $(M=5 \mathrm{msec})$, signifying a reduction in the effect of the location-word mapping similar to that reported by Notebaert et al. (2007). The latter interaction reflects that RT decreased more across blocks when the Simon trials were mixed with English words $(M D=99 \mathrm{msec})$ than with Spanish words $(M D=43 \mathrm{msec})$. Language entered into a two-way interaction with correspondence for both $\mathrm{RT}$ and $\mathrm{PE}\left[F \mathrm{~s}(1,54)=6.35\right.$ and $4.12, M S_{\mathrm{e}} \mathrm{s}=1,724$ and 17.57, $p \mathrm{~s}<.015$ and .047]: The Simon effect was evident when the trials were mixed with those using Spanish words $(M \mathrm{~s}=15 \mathrm{msec}$ and $1.28 \%)[F \mathrm{~s}(1,54)=11.51$ and $5.12, p \mathrm{~s}<.002$ and .028 , for RT and PE, respectively], but not when they were mixed with those using English words $(M=2 \mathrm{msec}$ and $0.14 \% ; F \mathrm{~s}<1)$.

Notably, there was no interaction of correspondence $X$ group $[F \mathrm{~s}(1,54)=0.03$ and 0.01$]$, and the language $\times$ correspondence interaction did not enter into a three-way interaction with group $\left[F_{\mathrm{s}}(1,54)=1.74\right.$ and $0.35, p \mathrm{~s}>$ .19] nor a four-way interaction with group and block $\left[F_{\mathrm{S}}(1,54)=0.33\right.$ and $\left.2.32, p \mathrm{~s}>.078\right]$. The only remaining significant effect was the three-way interaction of language $\times$ correspondence $\times$ block for PE $[F(3,162)=$ $\left.3.19, M S_{\mathrm{e}}=7.37, p<.025\right]$. Simple effect analyses showed that the correspondence $\times$ block interaction was not significant for intermixed Spanish words $(F<1)$, but approached the .05 level for intermixed English words $[F(3,162)=2.51, p<.06]$, where the Simon effect tended to increase from the first to the last block.

Sequential effects. The RT and PE data for both tasks were analyzed for sequential effects on the basis of the relation of the task for the present trial to that for the previous trial (task repetition or task switch). The analyses were the same as the main analyses reported for the locationrelevant and irrelevant trials, except that the repetition/ switch variable replaced that of block. Only significant effects involving the task repetition variable are reported. For the location-relevant trials, repetition/switch yielded a main effect for both RT and PE $\left[F_{\mathrm{S}}(1,54)=373.38\right.$ and 67.90, $M S_{\mathrm{e}} \mathrm{s}=3,227$ and 8.26, $p \mathrm{~s}<.001$ ], with performance better for task-repetition trials $(M \mathrm{~s}=664 \mathrm{msec}$ and $2.88 \%)$ than for task-switch trials $(M \mathrm{~s}=811 \mathrm{msec}$ and $6.04 \%$ ). For RT, the two-way interaction with group (bilingual or monolingual) $\left[F(1,54)=4.18, M S_{\mathrm{e}}=3,227, p=\right.$

Table 4

Mean Reaction Time (RT) and Percent Error (PE) for Location-Relevant Trials As a Function of Group, Language, and Block in Experiment 2

\begin{tabular}{lcccc}
\hline & \multicolumn{4}{c}{ Language } \\
\cline { 2 - 3 } Block & RT & PE (\%) & RT & PE (\%) \\
\cline { 2 - 5 } \cline { 4 - 5 } 1 & Monolingual English Participants \\
2 & 748 & 4.29 & 677 & 2.14 \\
3 & 691 & 2.96 & 654 & 2.41 \\
4 & 667 & 3.23 & 651 & 2.52 \\
Overall & 669 & 2.81 & 624 & 2.65 \\
\multicolumn{5}{c}{ Bilingual English/Vietnamese Participants } \\
1 & 773 & 6.00 & 796 & 6.56 \\
2 & 715 & 5.93 & 741 & 5.79 \\
3 & 715 & 4.89 & 715 & 5.71 \\
4 & 688 & 3.92 & 705 & 5.37 \\
Overall & 723 & 5.19 & 739 & 5.86 \\
\hline
\end{tabular}


Table 5

\begin{tabular}{|c|c|c|c|c|c|c|c|c|}
\hline \multirow[b]{4}{*}{ Block } & \multicolumn{8}{|c|}{$\begin{array}{c}\text { Mean Reaction Time (RT) and Percent Error (PE) } \\
\text { As a Function of Group, Language, Correspondence, } \\
\text { and Block for Location-Irrelevant Trials in Experiment } 2\end{array}$} \\
\hline & \multicolumn{4}{|c|}{ Intermixed English Words } & \multicolumn{4}{|c|}{ Intermixed Vietnamese Words } \\
\hline & \multicolumn{2}{|c|}{$\begin{array}{l}\text { Corresp. } \\
\end{array}$} & \multicolumn{2}{|c|}{ Noncorresp. } & \multicolumn{2}{|c|}{ Corresp. } & \multicolumn{2}{|c|}{ Noncorresp. } \\
\hline & RT & PE (\%) & RT & PE (\%) & RT & PE (\%) & RT & PE $(\%)$ \\
\hline \multicolumn{9}{|c|}{ Monolingual English Participants } \\
\hline 1 & 761 & 3.53 & 731 & 2.25 & 694 & 3.09 & 699 & 3.65 \\
\hline 2 & 711 & 3.60 & 704 & 1.91 & 671 & 4.25 & 681 & 3.82 \\
\hline 3 & 689 & 3.07 & 671 & 2.87 & 663 & 3.42 & 675 & 3.20 \\
\hline 4 & 680 & 2.51 & 685 & 3.55 & 655 & 3.66 & 662 & 3.57 \\
\hline Overall & 710 & 3.18 & 698 & 2.64 & 671 & 3.60 & 679 & 3.56 \\
\hline \multicolumn{9}{|c|}{ Bilingual English/Vietnamese Participants } \\
\hline 1 & 749 & 5.68 & 744 & 3.75 & 744 & 6.62 & 743 & 3.62 \\
\hline 2 & 698 & 4.83 & 683 & 3.86 & 693 & 5.29 & 698 & 5.14 \\
\hline 3 & 693 & 4.80 & 697 & 4.09 & 683 & 3.16 & 675 & 4.29 \\
\hline 4 & 674 & 4.67 & 680 & 3.29 & 660 & 5.31 & 679 & 5.36 \\
\hline Overall & 703 & 4.99 & 701 & 3.75 & 695 & 5.09 & 699 & 4.60 \\
\hline
\end{tabular}

.046] was also significant. The difference in RT between task-repetition and task-switch trials was larger for the bilingual group ( $M \mathrm{~s}=713$ and $876 \mathrm{msec}$, respectively) than for the monolingual group $(M \mathrm{~s}=615$ and $746 \mathrm{msec}$, respectively). This difference could be just a proportional increase due to the longer overall mean RT for the bilingual group, but the important point is that the switch costs were no smaller for bilinguals than for monolinguals.

For the location-irrelevant task, there was a main effect of repetition/switch for RT and PE $\left[F_{\mathrm{S}}(1,54)=249.07\right.$ and 73.86, $M S_{\mathrm{e}} \mathrm{s}=9,825$ and $\left.16.10, p \mathrm{~s}<.001\right]$, and this variable did not enter into any interaction involving group. Performance was better for task-repetition trials $(M \mathrm{~s}=$ $652 \mathrm{msec}$ and $2.38 \%)$ than for task-switch trials $(M \mathrm{~s}=$ $800 \mathrm{msec}$ and 5.64\%).

\section{Discussion}

Performance on the location-relevant trials establishes that the bilingual participants were affected relatively more by the Spanish location words than were the monolingual English participants. For the English words, the monolingual participants were somewhat faster in responding than the bilingual participants, but made more errors. Thus, taking both RT and PE into account, there was little difference in difficulty of responding to the words in the primary English language for both groups. For the Spanish words, the bilingual participants had relatively greater difficulty than did the monolingual participants, as indicated by shifts to a larger RT difference between the two groups and a relatively higher error rate for the bilingual participants. As noted, this difficulty is to be expected due to the Spanish words, which are meaningful to the bilingual participants, being mapped incompatibly to the responses. Thus, these results confirm that the bilingual participants were approximately as fluent as the monolingual group with the English language and more fluent than them with the Spanish language.

Importantly, the influence of the intermixed locationword-relevant trials on performance of the Simon task trials is unambiguous. The English monolingual group rep- licated the customary finding of little Simon effect overall when the incompatibly mapped English words were interspersed, but they showed a substantial Simon effect when the incompatibly mixed Spanish words were interspersed. This outcome indicates that the Spanish location words had little meaning to the monolingual English participants. The bilingual Spanish/English participants showed the same result pattern. When the intermixed trials used English words from their primary language, the Simon effect was absent overall. However, when those trials used Spanish words from the participants' first language, the bilingual participants showed a standard Simon effect. Thus, the results are consistent with the hypothesis that the main factor of importance is whether the language is the participants' primary language, not that it should be the one they learned first. This conclusion is in agreement with Basnight-Brown and Altarriba (2007), whose experiments examined cross-language priming in lexical decision tasks.

Bilinguals showed longer mean RTs for both tasks than did the monolinguals. Furthermore, there was no difference in size of the RT Simon effect between monolinguals and bilinguals for the location-irrelevant task. These results obtained with mixed tasks are in contrast to those reported by Bialystok et al. (2004) with pure Simon tasks, for which bilinguals showed shorter RT overall and a reduced Simon effect, compared with monolinguals. Additionally, bilinguals in the present study showed task-switch costs that were at least as large as those shown by monolinguals, whether the present trial was location-relevant or locationirrelevant. The absence of a benefit for bilinguals in this experiment, in which tasks are mixed, contrasts with the bilingual advantage shown in a task for which response switches occur frequently (Bialystok, 2006).

\section{EXPERIMENT 2}

The Spanish and English languages spoken by the bilingual participants in Experiment 1 are members of the Indo-European family of languages and share many 
similarities. Both are based on the Latin alphabet and are phonetic, with many cognates. Also, neuropsychological evidence suggests that the two languages share a common semantic system (Illes et al., 1999).

Valaki et al. (2004) showed different patterns of neurophysiological activity for Spanish and English compared with a member of the Austro-Asiatic family, Mandarin Chinese. In Experiment 2, we used an Austro-Asiatic language, Vietnamese, in addition to English. Vietnamese also uses the Latin alphabet, with additional diacritical marks, but because it is part of the Austro-Asiatic family of languages, Vietnamese bears less similarity to English than does Spanish. Differences include the fact that Vietnamese is a tonal language for which intonation is more important, with much of the vocabulary and pronunciation adopted from Cantonese Chinese. Because Vietnamese is processed more distinctly from English than is Spanish, it may be coded in a separate representational system; if so, Vietnamese could be treated like the primary language when that language system is activated, thus showing similar results to English words for the bilinguals. Therefore, Experiment 2 provides a test of whether incompatibly mapped location words in the secondary language influence the spatial Simon effect less than those in the primary language when the two languages are from different families.

\section{Method}

Participants. Fifty-six participants were recruited from California State University Long Beach and its surrounding community through the Psychology Department participant pool, fliers, and word-of-mouth recruitments. Twenty-eight were monolingual English participants (6 males, 22 females; categorized as 13 Caucasian, 7 non-Vietnamese Asians, 1 Hispanic, 1 African American, and 7 mixed race), and 28 were Vietnamese/English bilingual participants (12 males, 16 females; all self-identified as Vietnamese Americans). All bilingual participants reported learning to speak Vietnamese as their first language and learning English soon thereafter, English now being their primary language (see Table 1 and the Appendix for demographic details). All monolingual participants reported speaking only English. As in Experiment 1, introductory psychology students received experimental credits, and other adult volunteers were paid $\$ 15$.

Apparatus, Stimuli, and Procedure. The apparatus and stimuli were the same as those used in Experiment 1, with the following differences. The Spanish words were replaced with the Vietnamese words trái (left) and phái (right; approximate sizes of $12 \times 6 \mathrm{~mm}$, or $\left.1.25^{\circ} \times 0.63^{\circ}\right)$. The procedure was similar to that in Experiment 1, with each participant performing two parts, one with each language, with order counterbalanced between subjects. After completing the RT tasks, participants filled out the demographic questionnaire and a vocabulary test similar to that in Experiment 1, except that the bilinguals received Vietnamese words rather than Spanish words.

\section{Results}

Location-relevant trials. Mean correct RT and PE were submitted to 2 (language) $\times 2$ (group) $\times 4$ (block) ANOVAs, with group as a between-subjects factor.

For both RT and PE, the main effect of block was significant $\left[F \mathrm{~s}(3,162)=59.72\right.$ and $5.01, M S_{\mathrm{e}} \mathrm{s}=2,076$ and 4.34, $p \mathrm{~s}<.005]$. Participants showed a practice effect, in which RT and PE decreased from the first block $(M \mathrm{~s}=$ $748 \mathrm{msec}$ and $4.75 \%)$ to the last one $(M \mathrm{~s}=671 \mathrm{msec}$ and $3.69 \%)$. The main effect of group $[F \mathrm{~s}(1,54)=4.29$ and $10.75, M S_{\mathrm{e}} \mathrm{s}=87,955$ and $72.99, p<.045$ and .002$]$ was also significant for both measures. RT was shorter and errors less common for monolingual English control participants $(M=673 \mathrm{msec}$ and $2.88 \%)$ than for bilingual Vietnamese participants $(M=731 \mathrm{msec}$ and $5.52 \%)$.

For RT, the two-way interaction of language $\times$ group $\left[F(1,54)=4.93, M S_{\mathrm{e}}=19,445, p<.032\right]$ was significant. For the English words, there was no significant difference in RT between the monolingual $(M=694 \mathrm{msec})$ and bilingual $(M=723 \mathrm{msec})$ groups $(F<1)$, but for the Vietnamese words the monolingual participants responded significantly faster $(M=652 \mathrm{msec})$ than did the bilingual participants $(M=739 \mathrm{msec})[F(1,54)=7.11$, $p<.020]$. No other effects were significant.

Location-irrelevant trials (Simon task). Mean correct RT and PE for the location-irrelevant trials were submitted to 2 (language) $\times 2$ (group) $\times 2$ (correspondence) $\times 4$ (block) ANOVAs. Again, group was the only between-subjects variable.

The only significant main effect was that of block for RT $\left[F(3,162)=41.68, M S_{\mathrm{e}}=3,966, p<.001\right]$. RT decreased from the first block $(M=733 \mathrm{msec})$ to the last one $(M=672 \mathrm{msec})$. The main effect of language approached the .05 level for RT $\left[F(1,54)=3.78, M S_{\mathrm{e}}=17,280, p=\right.$ $.057]$, and the interaction of language with correspondence attained statistical significance $\left[F(1,54)=7.32, M S_{\mathrm{e}}=\right.$ $1,427, p<.010]$. RT tended to be shorter when the intermixed trials were Vietnamese words $(M=686 \mathrm{msec})$ than when they were English words $(M=703 \mathrm{msec})$. More important, the Simon effect was larger when the intermixed words were Vietnamese $(M=6 \mathrm{msec})$ rather than English $(M=-8 \mathrm{msec})$. No other effects were significant, including the three-way interaction of the latter two variables with group $[F \mathrm{~s}(1,54)=2.37$ and $0.05, p \mathrm{~s}>.125]$ and the four-way interaction with block $\left[F_{\mathrm{s}}(3,162)=1.56\right.$ and $2.69, p \mathrm{~s}>.052]$.

Sequential effects. As in Experiment 1, the RT data for both tasks were analyzed for sequential effects in relation to the immediately preceding trial. For the location-relevant task, repetition/switch had a main effect $[F \mathrm{~s}(1,54)=$ 198.25 and 59.57, $M S_{\mathrm{e}} \mathrm{s}=5,408$ and 8.18, $\left.p \mathrm{~s}<.001\right]$. Performance was better for task-repetition trials $(M \mathrm{~s}=$ $634 \mathrm{msec}$ and $2.69 \%)$ than for task-switch trials $(M \mathrm{~s}=$ $773 \mathrm{msec}$ and $5.64 \%$ ). For RT, there also was a three-way interaction with group and language $[F(1,54)=5.80$, $\left.M S_{\mathrm{e}}=2,480, p<.020\right]$. For English words, the bilingual participants showed no difference in switch costs $(M \mathrm{~s}=$ 653 and $791 \mathrm{msec}$ for task-repetition and task-switch trials, respectively) from the monolingual participants ( $M \mathrm{~s}=$ 620 and $770 \mathrm{msec}$, respectively) $(F<1)$. For Vietnamese words, though, the switch costs for the bilinguals $(M \mathrm{~s}=$ 660 and $819 \mathrm{msec}$, respectively) were larger than those for the monolinguals ( $M \mathrm{~s}=605$ and $712 \mathrm{msec}$, respectively) $[F(1,54)=6.23, p=.016]$. As in Experiment 1, this difference in switch costs could be a scaling effect related to the difference in overall mean RT.

For the location-irrelevant task, the main effect of repetition/switch was again significant for RT and PE $\left[F \mathrm{~s}(1,54)=217.53\right.$ and $49.74, M S_{\mathrm{e}} \mathrm{s}=10,631$ and 21.04, 
$p \mathrm{~s}<.001]$. Performance was better for task-repetition trials $(M \mathrm{~s}=623 \mathrm{msec}$ and $2.40 \%)$ than for task-switch trials $(M \mathrm{~s}=767 \mathrm{msec}$ and $5.45 \%)$. This factor did not enter into any interactions with group, indicating that the switch costs were similar for bilinguals and monolinguals.

\section{Discussion}

As in Experiment 1, the location-relevant task provided evidence that the bilingual participants were fluent in both English and Vietnamese. Bilingual participants showed RT to incompatibly mapped English words that did not differ significantly from that for the monolingual participants, suggesting that the word meanings were being processed similarly by the two groups. In contrast, RT to incompatibly mapped Vietnamese words was significantly longer for the bilinguals than that for the monolingual English participants, indicating that the bilinguals' performance was being influenced more by the word meanings, which should slow responding because of their incompatible mapping to the responses.

For the location-irrelevant task, correspondence again interacted with language, with the Simon effect being less positive when the intermixed trials were English words than when they were Vietnamese words. The difference in effect sizes was $14 \mathrm{msec}$ in this experiment, compared with $13 \mathrm{msec}$ for English and Spanish words in Experiment 1. Thus, even though the English and Vietnamese languages differ more than do English and Spanish, bilinguals and monolinguals showed similar patterns of processing for the two language pairs. Comparison across experiments highlights this point. When the data sets from both experiments were combined, with experiment added as a factor, the language $\times$ correspondence interaction for RT, which was significant in each experiment individually, did not show an interaction with experiment $(F<1)$. Also, in Experiment 2, as in Experiment 1, the bilingual participants showed no smaller Simon effect or switch costs than did the monolingual participants.

\section{GENERAL DISCUSSION}

Kroll and Stewart's (1994) model of bilingualism assumes that words from both languages activate a shared conceptual representation, with activation from the first language being stronger than that from the second language. Notebaert et al. (2007) proposed a model for processing of spatial information that postulates this conceptual representation's being also activated by visuospatial stimuli. They tested this model by taking advantage of the finding that when trials with incompatible mapping of the words left and right to left and right keypresses are intermixed with trials on which stimuli occur in left and right locations but responses are to be based on stimulus color, the Simon effect for the latter trials is eliminated (Proctor et al., 2000; Proctor $\&$ Vu, 2002). For native Dutch speakers fluent in French, Notebaert et al. showed that this elimination of the Simon effect occurred when the location words were in Dutch but not in French. They interpreted this finding as indicating that the first language activates shared spatial representations with those of physical loca- tions, but the second language does so only to a much lesser extent.

Evidence from lexical decision and other tasks suggests that the critical factor is the strength of the language, which implies that the amount that a language is used on a daily basis is more important than whether it is the first acquired (Basnight-Brown \& Altarriba, 2007; Fillmore, 2005). In the present study, we examined performance of bilingual English/Spanish and English/Vietnamese participants for whom English was learned second but became their primary language. This allowed dissociation of whether the language was learned first from the primary/secondary status later in life. It also enabled us to assess the generalizability across groups who speak an Indo-European language and an Austro-Asiatic language versus those who speak two Indo-European languages.

Demographic data (see the Appendix) confirmed that the bilingual participants were relatively more fluent in English but had learned their mother language first. Both English/Spanish and English/Vietnamese bilinguals indicated that they had learned English on average 2 to 3 years after the other language. Both groups also indicated that they currently speak and read English more fluently than they do their first language. Performance on the locationrelevant trials of the experiments confirmed the statements about relative fluency. Neither those who were fluent in Spanish nor those who were fluent in Vietnamese showed performance much different from that of the monolingual English participants for trials on which they were to respond incompatibly to the English word left or right. When the words were in their native language, though, both bilingual groups showed greater difficulty than the monolingual groups, indicating that the word meanings (which were mapped incompatibly to responses and thus should interfere) were being processed more by those fluent in that language.

For the location-irrelevant trials of the Simon task, the results were relatively unambiguous. Monolingual English participants showed no Simon effect in either experiment when trials with English words were intermixed with Simon trials for which stimulus location was irrelevant, consistent with previous findings (e.g., Proctor et al., 2000). Moreover, in both experiments, the Simon effect was significantly larger for the monolingual participants when the words were from the language in which they were not fluent, consistent with the view that elimination of the Simon effect is mainly a consequence of the incompatible mapping of location-word meanings. Of most importance, the bilingual participants showed a similar pattern of results, with the Simon effect being larger when the words were in their first language learned than when they were in English. This outcome indicates that it is the primary language, not the first language learned, that strongly activates shared spatial representations with physical locations. In the present study, the Simon effect was absent in all cases when the intermixed words were in English, leaving open the possibility that a unique feature of the words in that language is involved. However, Notebaert et al. (2007) showed a similar elimination of the Simon effect for Dutch/French bilinguals when the words were in 
Dutch, results that converge to provide evidence against a language-specific account of the elimination and for the hypothesis that language experience is the critical factor.

Bialystok et al. (2004) found that bilinguals (English/ Tamil or English/Cantonese) showed a smaller Simon effect than did monolinguals in a pure Simon task and shorter RTs overall, findings that they attributed to the bilinguals having developed enhanced executive control processes. In the mixed tasks context of the present experiments, bilingual participants showed Simon effects that did not differ in size from those of monolingual participants, and their overall RTs were no shorter. Moreover, for both bilingual and monolingual participants, RT was longer and error rate higher on trials for which the task switched from the preceding trial, compared with trials for which the task repeated. These task-switch costs were also at least as large for the bilinguals as for the monolinguals, both for the location-word-relevant task and the Simon task. Our findings of no difference in overall RT, Simon effect sizes, or sequential effects provide no indication of more efficient executive control processes for bilinguals when performing Simon task trials mixed with trials of incompatibly mapped location words.

Differences in Simon effect sizes between bilinguals and monolinguals have not always been obtained in studies using pure Simon tasks (Bialystok \& DePape, 2009; Morton \& Harper, 2007). However, the overall RT benefit for bilinguals when performing the Simon task has been found more reliably (but see Morton \& Harper, 2007). One possible reason why we did not find an overall benefit in RT for the bilinguals with mixed tasks is that one of the tasks used words. Words in a known language may be processed less proficiently by bilinguals than by monolinguals, offsetting the advantage of more efficient executive control processes (see, e.g., Bialystok \& Feng, 2009). It is not possible to determine whether inclusion of verbal materials is a critical factor in our study, but if so, the verbal-processing disadvantage for bilinguals must also influence performance on Simon trials, for which the stimuli are not verbal.

With regard to sequential effects, the pattern of results we obtained for task switching is not much different from that obtained by Bialystok (2006) for response switching under pure task conditions. She found a small overall benefit in RT for bilinguals under high switch conditions, but it was limited to stimuli for which the direction of an arrow head provided the irrelevant location information. The costs associated with a response switch on a trial as opposed to a response repetition did not differ significantly for bilinguals and monolinguals, similar to the results we obtained with task switching. Taken together, these findings suggest that the bilingual benefit for handling switches is dependent on task demands.

Both our study and that of Notebaert et al. (2007) used written words, and it is not apparent whether similar differences in processing would exist for spoken-word stimuli. We are not aware of any auditory equivalents of the visual mixing studies that have been conducted, but studies could be performed in which people respond to an attribute of tone stimuli, such as pitch presented from left or right locations and spoken words from a centered location. Whether a similar reduction of the Simon effect would occur in that situation is unknown, but if so, the influence of the different languages for bilingual participants could show a different pattern than in the studies using visual stimuli. In the present study, particularly for the English/Vietnamese bilinguals, the difference in fluency between spoken forms of the two languages was indicated by participants to be less than that between written forms. This would coincide with the native language likely being used regularly at home for oral communication with family members and members of the local community, but English being used more often at work and at school, where reading and writing are more prominent (see, e.g., Mackey, 2000). Thus, the asymmetry in processing the two languages evident with written location words may not be as pronounced with spoken location words.

We end by noting the robustness of the primary findings for the influence of intermixed trials of incompatibly mapped location words on the Simon effect for physical locations. The Simon effect has been shown to be eliminated when the words are from the primary language of monolinguals whose primary language is English and bilingual speakers of Dutch/French, English/Spanish, and English/Vietnamese. This elimination has been shown not to occur when the words are from the secondary language of the bilinguals for languages of French, Spanish, and Vietnamese. The evidence thus points to these robust effects as reflecting broadly generalizable, qualitative differences in the way in which spatial information from words in the primary and secondary languages is processed. The generalizability of the findings from the studies to date using the mixed tasks paradigm suggests that variants of it can be used as a tool for investigating other possible differences in the processing of primary and secondary languages.

\section{AUTHOR NOTE}

This study was supported in part by NASA Cooperative Agreement NNX09AU66A and U.S. Army Research Office MURI Grant W911NF-05-1-0153. Correspondence regarding this article should be sent to K.-P. L. Vu, Department of Psychology, California State University Long Beach, 1250 N. Bellflower Blvd., Long Beach, CA 90840 (e-mail:kvu8@csulb.edu).

\section{REFERENCES}

Basnight-Brown, D. M., \& Altarriba, J. (2007). Differences in semantic and translation priming across languages: The role of language direction and language dominance. Memory \& Cognition, 35, 953965.

BialystoK, E. (2006). Effect of bilingualism and computer video game experience on the Simon task. Canadian Journal of Experimental Psychology, 60, 68-79.

Bialystok, E., Craik, F. I. M., Klein, R., \& Viswanathan, M. (2004). Bilingualism, aging, and cognitive control: Evidence from the Simon task. Psychology \& Aging, 19, 290-303.

Bialystok, E., \& DePAPE, A. M. (2009). Musical expertise, bilingualism, and executive functioning. Journal of Experimental Psychology: Human Perception \& Performance, 35, 565-574.

BiALYstoK, E., \& Feng, X. (2009). Language proficiency and executive control in proactive interference: Evidence from monolingual and bilingual children and adults. Brain \& Language, 109, 93-100.

BIRDSONG, D. (2005). Interpreting age effects in second language ac- 
quisition. In J. F. Kroll \& A. M. B. De Groot (Eds.), Handbook of bilingualism (pp. 109-127). New York: Oxford University Press.

Fillmore, L. W. (2005). When learning a second language means losing the first. In M. M. Suárez-Orozco, C. Suárez-Orozco, \& D. B. Qin (Eds.), The new immigration: An interdisciplinary reader (pp. 289308). New York: Routledge.

Illees, J., Francis, W. S., Desmond, J. E., Gabrieli, J. D. E., Glover, G. H., POLDRACK, R., ET AL. (1999). Convergent cortical representation of semantic processing in bilinguals. Brain \& Language, 70, 347-363.

Kroll, J. F., \& De Groot, A. M. B. (EDS.) (2005). Handbook of bilingualism. New York: Oxford University Press.

Kroll, J. F., \& Stewart, E. (1994). Category interference in translation and picture naming: Evidence for asymmetric connections between bilingual memory representations. Journal of Memory \& Language, 33, 149-174.

Lu, C.-H., \& Proctor, R. W. (1995). The influence of irrelevant location information on performance: A review of the Simon and spatial Stroop effects. Psychonomic Bulletin \& Review, 2, 174-207.

MACKeY, W. F. (2000). The description of bilingualism. In L. Wei (Ed.), The bilingualism reader (pp. 22-50). London: Routledge.

Morton, J. B., \& HARPER, S. N. (2007). What did Simon say? Revisiting the bilingual advantage. Developmental Science, 6, 719-726.

Notebaert, W., De Moor, W., Gevers, W., \& Hartsuiker, R. J. (2007). New visuospatial associations by training verbospatial mappings in the first language. Psychonomic Bulletin \& Review, 14, 1183-1188.

Proctor, R. W., Marble, J. G., \& VU, K.-P. L. (2000). Mixing incom- patibly mapped location-relevant trials with location-irrelevant trials: Effects of stimulus mode on the reverse Simon effect. Psychological Research, 64, 11-24.

Proctor, R. W., \& Vu, K.-P. L. (2002). Mixing location-irrevelant and location-relevant trials: Influence of stimulus mode on spatial compatibility effects. Memory \& Cognition, 30, 281-293.

Proctor, R. W., \& Vu, K.-P. L. (2006). Stimulus-response compatibility principles: Data, theory, and application. Boca Raton, FL: CRC Press.

Schoonbaert, S., Duyck, W., Brysbaert, M., \& Hartsuiker, R. J. (2009). Semantic and translation priming from a first language to a second and back: Making sense of the findings. Memory \& Cognition, 37, 569-586.

Simon, J. R. (1990). The effects of an irrelevant directional cue on human information processing. In R. W. Proctor \& T. G. Reeve (Eds.), Stimulus-response compatibility: An integrated perspective (pp. 3186). Amsterdam: North-Holland.

Stürmer, B., Leuthold, H., Soetens, E., Schröter, H., \& SomMER, W. (2002). Control over location-based response activation in the Simon task: Behavioral and electrophysiological evidence. Journal of Experimental Psychology: Human Perception \& Performance, 28, 1345-1363.

Valaki, C. E., Maestu, F., Simos, P. G., Zhang, W., Fernandez, A., AMo, C. M., ET AL. (2004). Cortical organization for receptive language functions in Chinese, English, and Spanish: A cross-linguistic MEG study. Neuropsychologia, 42, 967-979.

\section{Analyses of Demographic and Fluency Questionnaires}

Means for the demographic and fluency questions are listed in Table 1. For Experiment 1, five separate one-way ANOVAs were performed to determine whether there were group differences in age, years of spoken English, fluency rating of spoken English, years of reading English, and fluency rating of reading English. Significant group differences were found in years of spoken English $[F(1,54)=12.29, p<.001]$, with monolingual participants indicating that they had spoken English $(M=18.6$ years) for more years than the bilingual $(M=$ 16 years) participants did. There was also a significant effect of group for fluency ratings in reading English $[F(1,54)=5.02, p=.029]$. Monolingual participants rated their fluency in reading English $(M=9.9)$ higher than did bilingual participants $(M=9.3)$.

For the bilingual participants, four additional paired sample $t$ tests were performed to compare their experience and fluency ratings of speaking and reading between English and Spanish. Participants reported speaking Spanish for a longer time than English $[t(27)=4.07, p<.001]$, which is expected, because Spanish was their first language. However, they rated their fluency in speaking and reading to be higher for English than for Spanish $[t(27)=3.32$ and $3.82, p$ s $<.005]$, respectively. The number of years reading English and Spanish was the only comparison that did not differ significantly.

For Experiment 2, five one-way ANOVAs were also performed to determine whether there were group differences in age, years of spoken English, fluency rating of spoken English, years of reading English, or fluency rating of reading English. The effect of age was significant, with bilingual participants averaging 2 years older than their monolingual counterparts $[F(1,54)=4.16, p<.05]$. There were no group differences in years of speaking or reading English, but the monolingual participants rated their fluency in speaking and reading English $(M \mathrm{~s}=9.8$ and 9.7, respectively) higher than did the bilingual participants ( $M \mathrm{~s}=9.0$ and 8.8 , respectively) $[F \mathrm{~s}(1,54)=11.95$ and $14.27, p \mathrm{~s}<.001]$.

Bilingual participants reported speaking Vietnamese for more years than they spoke English $[t(27)=3.29$, $p<.005$ ], reflecting that Vietnamese was their first language. However, they indicated that they were able to read English for more years than they could Vietnamese $[t(27)=2.85, p<.01]$ and also rated their fluency in speaking and reading to be higher for English than for Vietnamese $[t(27)=4.34$ and 6.55, $p \mathrm{~s}<.001]$. The latter findings emphasize that English is their primary language. 